\title{
ANALISA PENERIMAAN DOSIS RADIASI PERMUKAAN KULIT PADA PEMERIKSAAN RADIOGRAFI THORAX PROYEKSI POSTERO ANTERIOR (PA)
}

\section{ANALYSIS RADIATION ACCEPTANCE ENTRANCE SKIN DOSE ON CHEST EXAMINATION ON POSTERO-ANTERIOR (PA) PROJECTION}

\author{
Darmini $^{1)}$, Arum Dwi Afriyani ${ }^{2)}$, Dwi Rochmayanti ${ }^{3)}$ \\ ${ }^{1,2,3)}$ Health Polytechnics of Semarang-Indonesia \\ e-mail :da12mini@gmail.com
}

\begin{abstract}
Background:Increasing tube voltage which balanced with decreasing tube current and exposure time, it can decrease patient dose. base on optimization principle of radiation protection and radiation safety, it must be some effort in order to make patient dose minimally as it needed to get diagnostic information. The purpose of this research are to find out radiation dose on $\mathrm{kV}$ which usually use in Radiology Departement, radiation dose on $\mathrm{kV}$ with higher than usual, and two find out radiation dose acceptance on both of technique was appropriate with reference dose that set by BAPETEN.

Methods : Type of this research was quantitative research with experimental approach. This research took place in laboratory 2 JTRR Semarang. This research had been done by illumination chest phantom which completed with TLD (Thermoluminisense Dosimeter) placed correct on central point on MSP (Mid Sagital Plane) as level as angulus inferior scapulae. Analyze data had been shown used tables by average accounting, compare between acceptance radiation dose on $\mathrm{kV}$ which usually use in Radiology Departement and on $\mathrm{kV}$ with higher than usual, and compare result radiation dose with reference dose that set by BAPETEN.

Results :The result of this research shown that there was difference acceptance radiation dose entrance skin on chest examination in posteroanterion projection on tube voltage which usually use in Radiology Departement, radiation dose on tube voltage with higher than usual. The average value of radiation dose on $\mathrm{kV}$ usually use in Radiology Departement was $0,059 \mathrm{mGy}$, while on tube voltage with higher than usual the average value of radiation dose was $0.020 \mathrm{mGy}$. The result of testing that used $\mathrm{kV}$ with higher than usual, acceptance radiation dose entrance skin which accepted was lower than on tube voltage usually use in Radiology Departement. The result of radiation dose on tube voltage usually use in Radiology Departement although used tube voltage with higher than usual, its value were lower than reference dose, it was $0,4 \mathrm{mGy}$ that set by BAPETEN.

Conclusion : Based on these results, using a higher tube voltage than is usually very useful to reduce the radiation dose received by the patient, then this technique should be applied in Radiology for the examination of the thorax with the PA that has a projection plane X-ray modality with high capability above $100 \mathrm{kV}$.
\end{abstract}

Keyword : Chest Examination, Radiation Dose

\section{PENDAHULUAN}

Sinar-X pertama kali ditemukan oleh seorang ahli fisika bernama Wilhelm Roentgen pada tahun 1895. Roentgen kemudian melihat potensi pemanfaatan terhadap sinar-X temuannya dapat diaplikasikan sebagai alat diagnostik medis. Salah satu sifat sinar-X adalah dapat menembus bahan dan massa. Daya tembus tersebut dipengaruhi oleh besarnya tegangan tabung yang digunakan dan tingkat kepadatan objek. Semakin tinggi tegangan tabung yang digunakan, semakin besar daya tembus sinar-X terhadap objek. Berdasarkan sifat tersebut sinar-X dimanfaatkan untuk melihat kelainan kelainan yang ada dalam tubuh (Bushong, 2001).

Di bidang radiodiagnostik, kualitas radiograf dipengaruhi oleh faktor eksposi. Disisi lain, pen ggunaan faktor eksposi harus menghasilkan penerimaan dosis radiasi pada pasien yang seminimal mungkin sesuai dengan prinsip ALARA (As Low As Reasonably Achievable), pemanfaatan sumber radiasi selalu menghendaki adanya penerimaan dosis yang serendah mungkin terhadap pasien, pekerja radiasi maupun masyarakat (Akhadi, 2000). Faktor eksposi terdiri atas tegangan tabung $(\mathrm{kV})$, arus tabung $(\mathrm{mA})$ dan waktu penyinaran (s) (Bushong, 2001). Tegangan tabung menentukan kualitas radiasi atau daya tembus sinar- $X$ yang dihasilkan. Arus tabung menentukan jumlah elektron yang akan melewati target sehingga dihasilkan sinar-X yang intensitas dan energinya cukup untuk menembus organ tertentu. Waktu penyinaran menentukan lamanya penyinaran sehingga menentukan kuantitas sinar-X yang dihasilkan.

Interaksi antara sinar- $\mathrm{X}$ dengan bahan dapat diteruskan, dihamburkan, dan diserap. Banyaknya foton sinar-X yang diteruskan dan dihamburkan akan berpengaruh terhadap kualitas radiograf, sedangkan foton sinar-X yang diserap akan berpengaruh terhadap dosis radiasi yang diterima pasien (Bushong, 2001).

Pemeriksaan radiodiagnostik bertujuan untuk memperoleh informasi yang jelas pada kelainan yang diderita oleh pasien. Jadi pencitraan pada film radiografi yang dihasilkan harus dapat memberi informasi yang dibutuhkan oleh dokter untuk mendiagnosa pasien yang menjalani pemeriksaan. Untuk mengoptimasi dosis radiasi yang diterima oleh pasien yang menjalani pemeriksaan dengan teknik radiodiagnostik, diperlukan adanya informasi dosis yang diterima pasien untuk optimasi proteksi radiasi dipenuhi dosis radiasi yang diterima.

Berbeda dengan dosis terhadap pekerja radiasi dan masyarakat, maka dosis penyinaran medik tidak dapat ditentukan nilai batasnya, karena ada faktor lain yang harus 
sesuai dengan tujuan diagnostik yang diharapkan. Dengan demikian, pembatasan penyinaran untuk melindungi pasien hanya dapat diberikan dalam bentuk batasan nilai sebagai petunjuk bagi pelaksana jenis pemeriksaan dengan menggunakan teknik radiodiagnostik.

Oleh karena itu, dosis radiasi yang diterima pasien dari suatu prosedur pencitraan diagnostik menjadi sebuah bahasan yang penting, mulai dari paralatan maupun teknik yang mesti digunakan. Dosimetri radiasi menjadi sesuatu yang menarik, karena jumlah dosis radiasi yang tersaji mengindikasikan resiko kerusakan jaringan biologi dari pasien. Efek biologi radiasi dapat dikelompokan menjadi deterministik dan stokastik (Bushberg, 2002). Menurut Perka BAPETEN Nomor 8 Tahun 2011 besaran dosis radiasi yang diterima masyarakat tidak melebihi $1 \mathrm{mSv}$ per tahun. Nilai panduan dosis radiasi permukaan kulit per radiografi pada pemeriksaan thorax proyeksi PA untuk pasien adalah 0,4 mGy.

Berdasarkan observasi peneliti di beberapa rumah sakit, penulis melihat bahwa pemeriksaan radiografi thorax merupakan pemeriksaan yang paling mendominasi diantara semua pemeriksaan radiografi lainnya. Namun, dalam pelaksanaannya di Rumah Sakit, pada pemeriksaan radiografi thorax selalu menggunakan tegangan tabung $(\mathrm{kV})$ rendah yaitu kurang lebih antara $55-70 \mathrm{kV}$ dan dengan mAs kurang lebih antara 5 - 10 mAs. Menurut Statkiwieckz (2006) penggunaan $\mathrm{kV}$ tinggi yang diimbangi dengan penurunan nilai $\mathrm{mA}$ dan $\mathrm{s}$ menyebabkan dosis pada pasien dapat dikurangi. Sementara itu, berdasarkan pasal 36 ayat 2 Perka BAPETEN Nomor 8 Tahun 2011 tentang penerapan optimisasi proteksi dan keselamatan radiasi harus diupayakan agar pasien menerima dosis radiasi serendah mungkin sesuai dengan yang diperlukan untuk mencapai tujuan diagnostik. Penelitian ini dibatasi untuk meneliti dosis radiasi pada pemeriksaan Thorax dengan tegangan tabung $(\mathrm{kV})$ standard dan tegangan tabung $(\mathrm{kV})$ lebih besar sama dengan $100 \mathrm{kV}$.

Tujuan penelitian ini adalah untuk mengetahui berapa dosis radiasi permukaan kulit pada pemeriksaan radiografi Thorax proyeksi Postero Anterior (PA) dengan menggunakan tegangan tabung yang biasa digunakan di Instalasi Radiolog dan tegangan tabung yang lebih tinggi serta mengetahui apakah dosis radiasi permukaan kulit pada pemeriksaan radiografi Thorax proyeksi Postero Anterior (PA) tersebut sudah sesuai dengan nilai panduan dosis radiasi permukaan kulit menurut Perka BAPETEN Nomor 8 Tahun 2011.

\section{METODE}

Penelitian ini adalah penelitian kuantitatif dengan pendekatan eksperimental. Penelitian dilakukan pada bulan April tahun 2014 di Laboratorium 2 JTRR Semarang. Metode pengumpulan data yang dilakukan dalam penelitian ini adalah dengan cara observasi melalui pengukuran, peneliti mengukur dosis radiasi permukaan kulit pada pemeriksaan thorax proyeksi Postero Anterior (PA). Penelitian ini dilakukan dengan melakukan eksposi pada phantom thorax yang telah diberi TLD (Thermoluminisense Dosimeter) tepat pada titik bidik yaitu MSP (Mid Sagital Plane)setinggi kedua angulus inferior scapula. Analisa data disajikan dalam bentuk tabel dengan menghitung rata-rata dosis yang diterima, membandingkan penerimaan dosis radiasi dengan tegangan tabung yang biasa digunakan di Instalasi Radiologi dan tegangan tabung yang lebih tinggi dari biasanya, serta membandingkan dengan nilai panduan dosis yang ditetapkan oleh Perka BAPETEN Nomor 8 Tahun 2011.

\section{HASIL}

Sebelum dilakukan pengujian, pesawat sinar-X yang akan digunakan, dilakukan pengujian untuk keluaran variasi $\mathrm{kV}$ dengan hasil seperti terlihat pada tabel 1 .

Tabel 1. Hasil uji output $k V$ test pada pesawat sinar-x Laboratorium 2 Jurusan teknik Radiodiagnostik dan Radioterapi Semarang

\begin{tabular}{|c|c|c|c|c|c|c|c|c|}
\hline \multirow{2}{*}{$\begin{array}{c}\text { Pengaturan } \\
\text { Tegangan } \\
\text { Tabumg } \\
\text { (kV) }\end{array}$} & \multirow{2}{*}{$\begin{array}{c}\text { Alus } \\
\text { Tabuug } \\
\text { (mA) }\end{array}$} & \multirow{2}{*}{$\begin{array}{c}\text { Waktu } \\
\text { Eksposi } \\
\text { (ms) }\end{array}$} & \multicolumn{4}{|c|}{$\begin{array}{c}\text { Nilai Keluaran } \\
\text { (Output) kV }\end{array}$} & \multirow{2}{*}{$\begin{array}{l}\text { Acc } \\
(\%)\end{array}$} & \multirow{2}{*}{$\begin{array}{c}\text { Ket } \\
(\leq \pm 5 \%)\end{array}$} \\
\hline & & & 1 & 2 & 3 & Mean & & \\
\hline 70 & 100 & 10 & 71,6 & 70,8 & 71,4 & 71,27 & 1,81 & Sesuai \\
\hline 55 & 100 & 10 & 55,2 & 55,6 & 55,8 & 55,5 & 0,91 & Sesuai \\
\hline 58 & 100 & 10 & 59,4 & 59,6 & 59,2 & 59,5 & 2,41 & Sesuai \\
\hline 60 & 100 & 10 & 61,6 & 61,3 & 61,6 & 61,5 & 2,5 & Sesuai \\
\hline 100 & 100 & 10 & 100,3 & 100,6 & 100,5 & 100,46 & 0,56 & Sesuai \\
\hline
\end{tabular}

Dari tabel diatas dapat diketahui bahwa pada setingan tegangan tabung 70 nilai accuracy $1.81 \%$, pada tegangan tabung 55 nilai accuracy $0.91 \%$, pada tegangan tabung 58 nilai accuracy $2.41 \%$, pada tegangan tabung 60 nilai accuracy 2,5\%, dan pada tegangan tabung 100 nilai accuracy $0,56 \%$. Dari kelima variasi setingan tegangan tabung diperoleh hasil nilai accuracy tidak melebihi batas toleransi $\leq \pm 5 \%$.

\section{Dosis Radiasi dengan Menggunakan tegangan tabung yang Biasa Digunakan Di Instalasi Radiologi.}

Eksposi dilakukan kepada phantom thorax yang diposisikan dengan proyeksi PA berdiri dengan FFD $180 \mathrm{~cm}$ menggunakan faktor eksposi yang biasa digunakan di Radiologi dan TLD (Thermoluminisense Dosimeter) diletakkan tepat pada titik bidik yaitu MSP (Mid Sagital Plane)setinggi angulus inferior scapula. Hasil pengukuran dosis radiasi permukaan kulit pada pemeriksaan thorax yaitu pada tabel 2 .

Tabel 2. Hasil pengukuran dosis radiasi permukaan kulit pada pemeriksaan thorax proyeksi postero anterior (PA) dengan menggunakan tegangan tabung standar yang digunakan di Instalasi Radiologi

\begin{tabular}{|c|c|c|c|c|c|c|}
\hline \multirow[b]{2}{*}{ No. } & \multicolumn{4}{|c|}{ Faktor Eksposi } & \multirow[b]{2}{*}{$\begin{array}{l}\text { No. } \\
\text { TLD }\end{array}$} & \multirow{2}{*}{$\begin{array}{c}\text { Hasil } \\
\text { pengukuran } \\
\text { dosis radiasi } \\
\text { (mGy) }\end{array}$} \\
\hline & $\begin{array}{c}\text { Tegangan } \\
\text { tabung } \\
\text { (kV) } \\
\end{array}$ & $\begin{array}{c}\text { Arus } \\
\text { tabung } \\
(\mathrm{mA}) \\
\end{array}$ & $\begin{array}{c}\text { Waktu } \\
\text { eksposi } \\
\text { (ms) }\end{array}$ & $\begin{array}{c}\text { Arus tabung } x \\
\text { waktu eksposi } \\
\text { (mAs) }\end{array}$ & & \\
\hline 1. & 55 & 100 & 80 & 8 & 82 & 0,062 \\
\hline 2. & 58 & 100 & 50 & 5 & 84 & 0,030 \\
\hline 3. & 60 & 100 & 63 & 6,3 & 85 & 0,070 \\
\hline 4. & 70 & 100 & 80 & 8 & 81 & 0,074 \\
\hline
\end{tabular}


Dari penelitian yang telah peneliti lakukan diketahui bahwa penerimaan dosis per radiografi permukaan kulit pada pemeriksaan radiografi thorax pada proyeksi postero-anterior (PA) dengan menggunakan tegangan tabung yang biasa digunakan di Instalasi Radiologi yaitu pada $70 \mathrm{kV}$ dan $8 \mathrm{mAs}$ adalah 0,074 mGy, pada $55 \mathrm{kV}$ dan $8 \mathrm{mAs}$ diperoleh 0,062 $\mathrm{mGy}$, pada $58 \mathrm{kV}$ dan $5 \mathrm{mAs}$ adalah $0,030 \mathrm{mGy}$, serta pada $60 \mathrm{kV}$ dan 6,3 mAs diperoleh 0,07 mGy. Hal tersebut sudah sesuai dengan nilai panduan dosis menurut Perka BAPETEN Nomor 8 Tahun 2011 tentang panduan dosis per radiografi pada pemeriksaan radiografi thorax proyeksi PA yaitu 0,4 mGy. Dari hasil tersebut berarti pemeriksaan radiografi thorax proyeksi PA dengan menggunakan faktor eksposi seperti diatas menghasilkan dosis yang tidak melebihi dari nilai panduan dosis yang telah ditetapkan.

\section{Dosis Radiasi Dengan Menggunakan Tegangan Tabung Yang Lebih Tinggi Dari Tegangan Tabung standar.}

Faktor eksposi yang digunakan untuk teknik tegangan tabung yang lebih tinggi dari biasanya diperoleh dari perhitungan perubahan tegangan tabung terhadap arus $\mathrm{x}$ waktu (mAs) menurut Jenkins (1988). Faktor eksposi didapatkan dengan perhitungan dari faktor eksposi yang biasa digunakan di Instalasi Radiologi yang kemudian dimasukkan ke dalam rumus, dan kemudian di dapatkan nilai faktor eksposi yang digunakan untuk teknik $\mathrm{kV}$ yang lebih tinggi dari biasanya. Rumus yang digunakan dalam perhitungan sebagaimana pada persamaan 1(Bushong, 2001)

$$
\frac{m A s_{2}}{m A s_{1}}=\frac{\left(k V_{1}\right)^{4}}{\left(k V_{2}\right)^{4}}
$$

$\mathrm{mAs}_{1}$ adalah arus tabung yang digunakan mula-mula, $\mathrm{mAs}_{2}$ adalah arus tabung yang diperoleh setelah perhitungan, $\mathrm{kV}_{1}$ adalah tegangan tabung yang digunakan mula - mula dan $\mathrm{kV}_{2}$ adalah tegangan tabung untuk $\mathrm{kV}$ tinggi. Digunakan rumus tersebut karena pada pemeriksaan tersebut digunakan intensifying screen. Setelah dilakukan perhitungan dengan rumus seperti diatas maka diperoleh faktor eksposi untuk teknik $\mathrm{kV} \geq 100$ sebagaimana ditujukkan pada tabel 3 .

Tabel 3. Perhitungan faktor eksposi yang digunakan untuk teknik tegangan tabung $(\mathrm{kV}) \geq 100$ dari tegangan tabung $(\mathrm{kV})$ standar

\begin{tabular}{ccccc}
\hline & & $\begin{array}{c}\text { Faktor Eksposi Mula - Mula } \\
\text { (standar) }\end{array}$ & \multicolumn{2}{c}{$\begin{array}{c}\text { Faktor Eksposi tegangan } \\
\text { tabung } \geq 100 \mathbf{~ k V}\end{array}$} \\
\cline { 2 - 5 } No. & $\begin{array}{c}\text { Tegangan } \\
\text { Tabung } \\
\text { (kV) }\end{array}$ & $\begin{array}{c}\text { Arus tabung } \mathbf{x} \\
\text { waktu eksposi } \\
\text { (mAs) }\end{array}$ & $\begin{array}{c}\text { Tegangan } \\
\text { Tabung } \\
\text { (kV) }\end{array}$ & $\begin{array}{c}\text { Arus tabung x } \\
\text { waktu eksposi } \\
\text { (mAs) }\end{array}$ \\
\hline 1. & 55 & 8 & 100 & 0,8 \\
2. & 58 & 5 & 100 & 0,6 \\
3. & 60 & 6,3 & 100 & 0,8 \\
4. & 70 & 8 & 100 & 2 \\
\hline
\end{tabular}

Berdasarkan tabel 3 dapat diketahui bahwa pada faktor eksposi mula - mula $70 \mathrm{kV}$ dan $8 \mathrm{mAs}$ yang diubah menjadi $100 \mathrm{kV}$ maka didapatkan nilai mAs sebesar 2 mAs. Pada faktor eksposi mula - mula $55 \mathrm{kV}$ dan $8 \mathrm{mAs}$ yang diubah menjadi $100 \mathrm{kV}$ didapatkan nialai mAs sebesar 0,8 mAs. Pada pengaturan faktor eksposi mula - mula $58 \mathrm{kV}$ dan $5 \mathrm{mAs}$ yang diubah menjadi $100 \mathrm{kV}$ didapatkan nilai mAs sebesar $0,6 \mathrm{mAs}$, serta pada pengaturan faktor eksposi mula - mula 60 $\mathrm{kV}$ dan 6,3 mAs yang diubah menjadi $100 \mathrm{kV}$ diperoleh nilai mAs sebesar 0,8 mAs. Hasil pengukuran dosis radiasi permukaan kulit pada pemeriksaan thorax yaitu pada tabel 4 .

Tabel 4. Hasil pengukuran dosis radiasi permukaan kulit pada pemeriksaan thorax proyeksi postero anterior (PA) dengan menggunakan tegangan tabung tinggi

\begin{tabular}{|c|c|c|c|c|c|c|}
\hline \multirow{2}{*}{ No. } & \multicolumn{4}{|c|}{ Faktor Eksposi } & \multirow{2}{*}{$\begin{array}{l}\text { No. } \\
\text { TLD }\end{array}$} & \multirow{2}{*}{$\begin{array}{c}\text { Hasil pengukuran } \\
\text { dosis radiasi (mGy) }\end{array}$} \\
\hline & kV & $\mathbf{m A}$ & $\mathrm{ms}$ & mAs & & \\
\hline 1. & 100 & 100 & 20 & 2 & 86 & 0,029 \\
\hline 2. & 100 & 100 & 8 & 0.8 & 88 & 0,023 \\
\hline 3. & 100 & 100 & 6 & 0.6 & 87 & 0,006 \\
\hline 4. & 100 & 100 & 8 & 0.8 & 89 & 0,023 \\
\hline
\end{tabular}

Dari penelitian yang telah peneliti lakukan diketahui bahwa penerimaan dosis per radiografi permukaan kulit pada pemeriksaan radiografi thorax proyeksi postero-anterior (PA) dengan menggunakan $\mathrm{kV}$ yang lebih tinggi dari biasanya adalah pada pengaturan faktor eksposi $100 \mathrm{kV}$ dengan $2 \mathrm{mAs}$ dihasilkan dosis radiasi sebesar $0,029 \mathrm{mGy}$, pada pengaturan $100 \mathrm{kV}$ dan $0,8 \mathrm{mAs}$ dihasilkan dosis radiasi sebesar 0,023 mGy, pada pengaturan $100 \mathrm{kV}$ dan 0,6 mAs diperoleh dosis radiasi sebesar 0,006 $\mathrm{mGy}$, serta pada pengaturan $100 \mathrm{kV}$ dan $0,8 \mathrm{mAs}$ didapatkan nilai dosis radiasi sebesar $0,023 \mathrm{mGy}$. Dosis radiasi yang dihasilkan dengan menggunakan $\mathrm{kV}$ tinggi tersebut sudah sesuai dengan Perka BAPETEN Nomor 8 Tahun 2011 tentang panduan dosis per radiografi pada pemeriksaan radiografi thorax proyeksi PA yaitu tidak melebihi 0,4 mGy. Dari hasil tersebut berarti pemeriksaan radiografi thorax proyeksi PA dengan menggunakan teknik $\mathrm{kV}$ tinggi menghasilkan dosis yang masih jauh dibawah dari nilai panduan dosis per radiografi menurut Perka BAPETEN nomor 8 tahun 2011.

Dalam penelitian ini, peneliti menggunakan teknik $\mathrm{kV}$ yang lebih tinggi dari biasanya untuk mengurangi dosis radiasi. Penyerapan dosis pada tubuh dipengaruhi oleh faktor eksposi, mAs mengatur kuantitas sinar-X, sedangkang $\mathrm{kV}$ mengatur kualitas sinar-X. Pemilihan $\mathrm{kV}$ yang tinggi menyebabkan daya tembus yang besar pada tubuh, sehingga didapatkan dosis yang rendah (Kumar, 2011).

Hubungan antara $\mathrm{kV}$ yang digunakan dengan dosis yang diterima pasien adalah berbanding terbalik. Apabila kV yang digunakan semakin tinggi maka dosis radiasi yang diterima oleh pasien akan semakin rendah. Tegangan tabung mempengaruhi dosis radiasi yang diterima. Dosis radiasi dapat dikurangi dengan menaikkan $\mathrm{kV}$ karena semakin tinggi $\mathrm{kV}$ maka semakin tinggi daya tembus sinar- $\mathrm{X}$ yang dihasilkan, sehingga sinar-X lebih banyak yang diteruskan daripada yang diserap oleh tubuh (Ball and Price, 1989). Pada penelitian yang telah peneliti lakukan pada pemeriksaan 
thorax proyeksi PA dosis radiasi permukaan kulit yang diterima semakin rendah diikuti dengan kenaikan nilai kVnya.

\section{Dosis Radiasi Dengan Menggunakan Tegangan Tabung Yang Biasa Digunakan Di Instalasi Radiologi Dan Tegangan Tabung $\geq 100$, jika Dibandingkan Dengan Perka BAPETEN Nomor 8 Tahun 2011.}

Nilai panduan dosis radiasi permukaan kulit per radiografi pada pemeriksaan thorax proyeksi PA untuk pasien menurut Perka BAPETEN Nomor 8 Tahun 2011 adalah 0,4 mGy. Untuk bisa dibandingkan dengan referensi tersebut ditunjukkan pada tabel 5.

Tabel 5. Hasil pengukuran dosis radiasi bila dibandingkan dengan Nilai panduan dosis radiasi permukaan kulit per radiografi pada pemeriksaan thorax proyeksi PA menurut perka BAPETEN Nomor 8 tahun 2011

\begin{tabular}{cccccccc}
\hline No & $\begin{array}{c}\text { kV biasa } \\
\text { (mGy) }\end{array}$ & Ket. $^{1}$ & $\begin{array}{c}\text { kV tinggi } \\
\text { (mGy) }\end{array}$ & Ket. $^{2}$ & $\begin{array}{c}\text { Selisih } \\
\text { Penerimaan } \\
\text { (mGy) }\end{array}$ & $\begin{array}{c}\text { Prosentase } \\
\text { Penurunan } \\
\text { Dosis (\%) }\end{array}$ & $\begin{array}{c}\text { Nilai } \\
\text { panduan } \\
\text { dosis }^{3} \\
\text { (mGy) }\end{array}$ \\
\hline 1. & 0,074118 & Aman & 0,029191 & Aman & 0,044927 & $60,62 \%$ & 0,4 \\
2. & 0,062626 & Aman & 0,023032 & Aman & 0,039594 & $63,22 \%$ & 0,4 \\
3. & 0,030878 & Aman & 0,006665 & Aman & 0,024213 & $78,42 \%$ & 0,4 \\
4. & 0,07027 & Aman & 0,023448 & Aman & 0,046822 & $66,63 \%$ & 0,4 \\
$\bar{x}^{* *}$ & 0,059473 & Aman & 0,020584 & Aman & 0,038889 & $65,39 \%$ & 0,4 \\
\hline
\end{tabular}

Ket : ${ }^{1}$ Nilai dosis yang dihasilkan dibandingkan dengan nilai panduan dosis

${ }^{2}$ Nilai rata - rata yang diperoleh

${ }^{3}$ Menurut Perka BAPETEN Nomor 8 tahun 2011

Berdasarkan hasil penelitian yang telah peneliti lakukan, dosis radiasi yang dihasilkan dengan menggunakan $\mathrm{kV}$ yang biasa digunakan di Instalasi Radiologi maupun dosis radiasi yang dihasilkan dengan menggunakan teknik $\mathrm{kV}$ yang lebih tinggi dari biasanya sama - sama mempunyai nilai dosis radiasi yang aman untuk diberikan kepada pasien karena nilainya masih kurang dari $0.4 \mathrm{mGy}$ yang merupakan nilai panduan dosis radiasi untuk permukaan kulit pada pemeriksaan thorax PA menurut Perka BAPETEN Nomor 8 Tahun 2011. Terjadi penurunan dosis radiasi dari penggunaan tegangan tabung yang biasa digunakan di Instalasi Radiologi dan pada penggunaan $\mathrm{kV}$ yang lebih tinggi dari biasanya, penurunan dosis radiasi yang dihasilkan berturut - turut adalah dari dosis mula - mula sebesar 0,074 mGy turun menjadi $0,029 \mathrm{mGy}$, dari $0,062 \mathrm{mGy}$ turun menjadi 0,023 $\mathrm{mGy}$, dari $0,030 \mathrm{mGy}$ turun menjadi $0,006 \mathrm{mGy}$ dan dari 0,070 mGy turun menjadi 0,023 mGy. Hal tersebut berarti dengan menggunakan teknik tegangan tabung yang lebih tinggi dari biasanya dosis yang dihasilkan akan jauh lebih rendah jika dibandingkan dengan penggunaan tegangan tabung yang biasa digunakan di Instalasi Radiologi. Selisih nilai rata - rata penerimaan dosis radiasi yang dihasilkan antara penggunaan tegangan tabung yang biasa digunakan di Instalasi Radiologi dan penggunaan tegangan tabung yang lebih tinggi dari biasanya sebesar 0,0388 mGy dengan prosentase rata - rata $65,39 \%$.

\section{DISKUSI}

Peningkatan tegangan tabung yang disertai dengan penurunan nilai mAs mempengaruhi penurunan dosis pasien. Ketika nilai tegangan tabung diturunkan tetapi nilai mAs ditingkatkan justru akan meningkatkan dosis pasien. Hal ini dikarenakan nilai mA mengontrol kuantitas atau banyaknya sinar-X yang dihasilkan. Dengan menurunkan nilai mAs maka akan menentukan jumlah elektron yang bertumbukan ke anoda per satuan waktunya, sehingga sinar-X yang dihasilkan menjadi lebih sedikit. Ditambah lagi dengan penggunaan nilai tegangan tabung yang tinggi sehingga dengan kuantitas sinar$\mathrm{X}$ yang dihasilkan dan dengan daya tembus sinar- $\mathrm{X}$ yang besar maka akan mengurangi terjadinya penyerapan energi sinar-X pada tubuh pasien yang berakibat menurunnya dosis pasien (Kumar, 2011).

Pemeriksaan radiografi thorax dengan proyeksi PA sebaiknya dilakukan dengan menggunakan teknik tegangan tabung tinggi karena dengan menggunakan teknik tersebut dosis yang diterima pasien akan lebih rendah apabila dibandingkan dengan penggunaan tegangan tabung yang biasa digunakan di Instalasi Radiologi. Hal tersebut sesuai dengan pasal 36 ayat 2 Perka BAPETEN Nomor 8 Tahun 2011 tentang penerapan optimisasi proteksi dan keselamatan radiasi harus diupayakan agar pasien menerima dosis radiasi serendah mungkin sesuai dengan yang diperlukan untuk mencapai tujuan diagnostik.

\section{SIMPULAN}

Berdasarkan hasil penelitian dan pembahasan dapat disimpulkan bahwa Dosis radiasi permukaan kulit yang dihasilkan pada pemeriksaan thorax proyeksi postero-anterior (PA) standar menggunakan tegangan tabung yang biasa digunakan di Instalasi Radiologi adalah 0,074 mGy; 0,062 $\mathrm{mGy}$; 0,030 mGy; dan 0,07 $\mathrm{mGy}$. Dosis radiasi permukaan kulit yang dihasilkan pada pemeriksaan thorax proyeksi postero-anterior (PA) dengan menggunakan teknik tegangan tabung yang lebih tinggi dari biasanya adalah 0,029191 mGy; 0,023 mGy; 0,006 mGy dan 0,023 mGy. Dengan menggunakan $\mathrm{kV}$ yang biasa digunakan di Instalasi Radiologi maupun dengan teknik tegangan tabung yang lebih tinggi dari biasanya dosis radiasi permukaan kulit yang diterima pada pemeriksaan thorax proyeksi postero-anterior (PA) tidak melebihi nilai panduan dosis per radiografi thorax PA sebesar $0,4 \mathrm{mGy}$.

Setelah diketahui bahwa dengan menggunakan tegangan tabung yang lebih tinggi dari biasanya sangat bermanfaat untuk menurunkan dosis radiasi yang diterima pasien, maka sebaiknya teknik ini diaplikasikan di Instalasi Radiologi untuk pemeriksaan thorax dengan proyeksi PA yang mempunyai modalitas pesawat sinar- $\mathrm{X}$ dengan kemampuan tinggi diatas $100 \mathrm{kV}$. 


\section{DAFTAR PUSTAKA}

Akhadi, M. 2000. Dasar-dasar Proteksi Radiasi. PT. Rineka Cicpa: Jakarta. Ball dan Price. 1989. Chesney's Radiographic Imaging. Fifth Edition. Blackwell Scientific Publication : Melbourne.

Bapeten. 2011. Keselamatan Radiasi Dalam Penggunaan Pesawat Sinar-X Radiologi Diagnostik Dan Intervensional: Jakarta.

Bushberg JT.Siebert, JA, Leidholdt, EM \& Boone, JM (2002) the Essential Physics of Medical Imaging, PA, UA, Lippincotf Williams \& wilking.

Bushong, 2001. Radiologic Science For Technologists Physics, Biology, and Protection. CV Mosby Company: Washington D.C

Jenkins, David. 1980. Radiographic Photography and Imaging Processes. An Aspen Publication : Maryland.

Kumar dkk, 2011. Evaluation On X-Ray Exposure Considering Tube Voltage and Exposure Time. Dalam www.ijest.info/docs/IJEST11-03-04274.pdf. Diakses pada 10 Mei 2014.

Statkiewcz, M,A, dkk. 2006. Radiation Protection In Medical Radiography. Fifth Edition. Mosby Inc : Canada. 